\title{
ENTRE ESPELHOS E INTERFERÊNCIAS: A PROBLEMÁTICA DA TRADUÇÃO PARA CLARICE LISPECTOR
}

\author{
André Luís Gomes \\ Universidade de São Paulo
}

[Ao se traduzir, corre-se] o risco de não parar nunca: quanto mais se revê, mais se tem que mexer e remexer nos diálogos ${ }^{1}$.

1.

Por necessidade financeira, Clarice Lispector exerceu, paralelamente à ficção e ao trabalho no jornal, a atividade de tradutora. ${ }^{2}$ Vale ressaltar que Clarice foi primeiramente admitida na imprensa como tradutora. Entre outros livros, traduziu a novela policial Curtain, que recebeu o título Cai o pano, publicada em 1976 pela Editora Record, do Rio de Janeiro. ${ }^{3}$

1 LISPECTOR, Clarice. “Traduzir procurando não trair”. Revista Jóia, n. 177, Rio de Janeiro, maio de 1968. Todas as citações referentes a esta crônica dar-se-ão a partir dessa edição. Ao final deste texto, transcrevemos a referida crônica.

2 Entre os documentos pessoais da autora, a Fundação Casa de Rui Barbosa (FCRB)guarda uma Certidão de inscrição de profissional autônomo, datada de 6.2.1975, em que consta, além do endereço, como atividades exercidas por Clarice Gurgel Valente a de "Escritora de livros e Tradutora”.

3 A década de 1970 parece ter sido aquela em que Clarice mais se dedicou à tradução, uma vez que neste período foi publicada a maioria dos textos traduzidos: BORGES, Jorge Luis. História dos dois que sonharam. Jornal do Brasil, Caderno B, Rio de Janeiro, 27.12.1969, p. 2. Reproduzido em: SCHWARTZ, Jorge (org.). Borges no Brasil. São Paulo: EdUnesp/ Imprensa Oficial, 2001, p. 313-315; WESTMACOTT, Mary (Agatha Christie). A carga. Rio de Janeiro: Editora Nova Fronteira, s.d.; LAINÉ, Pascal. A rendeira. Rio de Janeiro: Imago Editora Ltda, 1975.; CHAGALL, Bella. Luzes acesas. Rio de Janeiro: Editora Nova Fronteira, s.d.; CHENSHW, Mary Ann. The natural way to super beauty. A receita natural para ser super bonita. Rio de Janeiro: Editora Artenova S.A., 1975; MENNINGER, Karl. O pecado de nossa época. Rio de Janeiro: Editora José Olympio, 1975. 
Se a produção de Clarice Lispector na imprensa já foi em grande parte publicada e motivou pesquisas, a atividade de tradutora merece ainda estudo.

Além de romances e contos, a escritora, geralmente junto com Tati Moraes, traduziu peças teatrais. Estas traduções não foram publicadas e os originais, em parte, estão reunidos na Fundação Casa de Rui Barbosa, revelando-se um primoroso objeto de pesquisa tendo em vista versões diferenciadas de alguns textos e as anotações manuscritas nas peças datilografadas, explicitando as minúcias de uma traduçóo. O inventário do arquivo 5 Clarice Lispector reúne as seguintes traduções:

A casa de Bernarda Alba, de Federico García Lorca

Hedda Gabler, de Ibsen

The member of the wedding, de Carson Mac Cullers ${ }^{4}$

Sotoba Komachi, de Yukio Mishima

Considerando as peças traduzidas e seus respectivos autores, poderíamos dizer, em um primeiro momento, que a aproximação de Clarice Lispector com o teatro se revela considerável e admirável. E se chegamos com mais facilidade a essas quatro peças traduzidas graças ao Inventário da Fundação, outras duas são citadas pela própria Clarice na crônica "Traduzir procurando não trair”, publicada na Revista Jóia. Nessa crônica, Clarice nos revela que traduziu três textos teatrais: uma peça de Lillian Hellman, outra de Tchecov e Hedda Gabler, de Ibsen. Hedda Gabler consta do Inventário, mas as outras não. Além disso, a autora não cita o título das peças teatrais, apenas o nome dos dramaturgos: Lillian Hellman e Tchecov. Chegamos ao nome das peças, pois descobrimos o programa de Os corruptos, título que recebeu o texto The little foxes, de Lillian Hellman, encenada pela Companhia Tônia Carrero. A atriz protagonizou a encenação, é citada na crônica e nos revelou que a peça de Tchecov traduzida era $A$ gaivota. ${ }^{5}$ Completamos

4 O Inventário do Arquivo não traz o autor da peça The member of the wedding, deixando uma incógnita marcada por um ponto de interrogação. Em uma coluna jornalística de Paulo Francis sobre teatro, "Estréias e Diversos", temos uma pequena nota que contém o nome do autor. Também, graças a essa nota, pode-se afirmar que o texto foi sido traduzido em 1961. Sobre esses dados, vamos nos deter quando comentarmos a tradução realizada por Clarice.

5 Em entrevista a mim concedida, Tônia Carrero forneceu as informações necessárias para se chegar ao título da peça de Tchecov. 
assim a lista de seis textos teatrais de alguns dos mais renomados dramaturgos, traduzidos por Clarice Lispector, sendo que algumas das traduções foram realizadas juntamente com Tati Moraes. ${ }^{6}$

2.

Apesar de ter traduzido vários contos, romances e as peças citadas, portanto exercendo a atividade de tradutora com certa constância principalmente na década de 60, Clarice pouco escreveu sobre o ato de traduzir, ${ }^{7}$ daí a importância da crônica tão específica sobre o assunto. Antes de nos determos nos textos dramatúrgicos, merecem ser comentados alguns trechos da crônica, ainda não publicada em livro, em que Clarice nos apresenta algumas reflexões sobre as dificuldades e as especificidades desta atividade, sendo mais específica ao abordar as traduções de textos teatrais.

O título da crônica, “Traduzir procurando não trair”, já manifesta a preocupação primeira da tradutora da necessária fidelidade ao autor, mas relativizada, pois não se é totalmente fiel, mas se procura, pelo menos, não trair, afinal se trata de uma mudança de códigos que exige adaptações, como a própria cronista afirma: "há a língua portuguesa que não traduz facilmente certas expressões americanas típicas, o que exige uma adaptação mais livre”.

No usufruto dessa liberdade intrínseca ao ato de traduzir é que reside o perigo de trair, e Clarice, no título e depois no desenvolvimento da crônica, demonstra sempre sua preocupação em ser o mais fiel possível ao original. A fidelidade ao texto original, na passagem de uma língua para outra,

6 A atriz Nydia Licia nos revelou em entrevista inédita, em 28 de novembro de 2003, que, geralmente, os jornais, ao divulgar ou comentar o espetáculo Hedda Gabler, mencionavam apenas o nome de Clarice como tradutora e que esta, indignada e descontente, lhe telefonou exigindo que o nome de Tati Moraes fosse também mencionado.

$7 \quad \mathrm{Na}$ FCRB, há várias cartas de Clarice sobre as traduções realizadas de seus romances e correspondências com seus tradutores. Há duas cartas, por exemplo, de Elizabeth Lowe: na primeira, de 28.11.1973, a tradutora pede autorização para publicar alguns contos de A legião estrangeira; na segunda, de 12.12.1977, Elizabeth escreve uma carta mais informal, pois se tornou amiga de Clarice e conta que está traduzindo Água viva com Earl Fitz. 
implica conhecimento das nuances de diversos aspectos de ambas as línguas para adequar o sentido construído em uma frase. A própria autora, que na década de 1960 já havia sido traduzida, comenta, por exemplo, sobre a tradução de um de seus livros que ela resolveu ler. Elogia, na crônica, a tradução do professor Gregory Rabassa pela Knopf, mas assume que não conseguiu ir até o fim.

Entretanto, o que vale ressaltar desse aspecto na crônica é o fato de Lispector comentar um trecho do prefácio em que o professor conclui que era mais difícil traduzi-la do que Guimarães Rosa, devido à sintaxe. Lispector reconhece que na passagem de uma língua para outra pesam detalhes dos mais variados aspectos gramaticais. Essas nuances se multiplicam quando se trata de uma passagem de uma linguagem para outra, como da literatura para o teatro e o cinema. E ela, em outro parágrafo da crônica, ao afirmar que busca tons diferenciados e procura adequar as falas às circunstâncias, realiza de forma consciente o trabalho intersemiótico a que se propõe:

E a exaustiva leitura da peça em voz alta para podermos sentir como soam os diálogos? Estes têm que ser coloquiais: de acordo com as circunstâncias, ora mais ou menos cerimoniosos, ora mais ou menos relaxados.

Clarice sempre disse que ficava enfadada ao reler seus textos e, como já comentamos, parece sentir o mesmo com as traduções, pois afirma que "quanto mais se revê o texto, mais se tem que mexer e remexer nos diálogos". Para ela, este é o grande risco da tradução: "não parar nunca”. E as coisas se transformam sempre em uma grande entrega, uma entrega exigente que sempre a consome, assim como suas personagens se abandonam e adentram jardins ou se deixam ser sugadas pelo outro: um animal, um inseto, um texto escrito ou a ser escrito. Parece ser esse o mesmo risco a que ela se refere: ser envolvida pela tradução a tal ponto que passe a ter a sensação de não poder parar nunca.

Entre essas considerações, Clarice acaba por nos revelar algumas de suas técnicas ao traduzir um texto. Por exemplo, a leitura em voz alta para sentir como soam os diálogos. Esclarece que a leitura em voz alta permite identificar o quanto os diálogos são coloquiais ou mais ou menos cerimoninsos. A tradutora não esconde sua preocupação com a "entonação" de cada personagem, para 
a qual precisa de "palavras e do tom apropriados”. Assim, a tradução, para Lispector, pressupõe pensar o texto enquanto encenação, ou seja, o tradutor deve interpretar os signos verbais tendo em vista o uso, na montagem teatral, também de signos nóo-verbais, o que configuraria o que Roman Jakobson denomina tradução intersemiótica (JAKOBSON, 1969, p. 64-65).

Essa preocupação de Clarice demonstra o conhecimento que a autora tem de técnicas teatrais utilizadas na escrita de um bom texto teatral. E a preocupação chega a ser até obsessiva, pois, segundo seu relato, uma vez repetiu tantas vezes em voz alta o texto que "pegou” a entonação americana nas inflexões de voz. O comentário de Tati Moraes, que auxiliou Clarice em suas traduções, ganha espaço na crônica: “Quem manda você ser uma atriz inata?”.

Clarice não discorda do comentário de Tati Moraes, pois acha que "todo escritor é um ator inato”. A crônica nos revela ainda o prazer e os dissabores da tradução, não só pelo ato de traduzir, mas também pelos elementos extrínsecos a ele, como a interferência do requisitante da tradução.

3.

Entre os textos teatrais, iremos nos deter, nesse texto, na análise da tradução que não foi concluída, a peça de Tchecov, mas provocou a escrita da crônica "Traduzir procurando não trair" e identificações a que a própria autora faz menção.

A tradução de $A$ gaivota, de Tchecov, ${ }^{8}$ ocorreu em um momento em que Clarice estava deprimida e a personagem principal a incomodava, pois se parecia demais com ela:

Depois eu soube que Tati andou consultando amigos meus para saber se me convinha lidar com o personagem principal, já que este se parecia demais comigo. A conclusão era que eu trabalhasse de qualquer maneira porque me faria bem agir, e porque seria bom eu ver, como num

\footnotetext{
8 A tradução da peça de Tchecov “passou para outras mãos” como Clarice nos informa na crônica citada. Como não tivemos acesso aos originais da tradução de Clarice e Tati Moraes, quando comentarmos a peça de Tchecov, utilizaremos a tradução de Bárbara Heliodora.
} 
espelho, a minha própria fisionomia. Que me faria bem lidar com um personagem cujo senso trágico da vida termina levando-o ao desespero. Traduzimos Tchecov, eu com um esforço tremendo. Pois parecia estar me descrevendo.

A preocupação de Tati Moraes, de fato, é pertinente, pois, ao traduzir essa peça, Clarice acaba lidando com Constantin Gavrilovitch Treplev, um jovem escritor que vive "no caos dos delírios e das imagens", sente-se fracassado profissional e amorosamente e tem um final trágico. Constantin é um escritor iniciante, entretanto é firme em suas concepções sobre sua arte, afirmando categoricamente que "precisamos de formas novas de expressão" (TCHÉKOV, 2000, p. 24) e "não se deve representar a vida como ela é e sim como a vemos em sonhos” (Idem, p. 27). O discurso metalingüístico e a inserção do teatro no teatro são utilizados, em A gaivota, justamente para se discutir concepções diferentes da arte de representar: Treplev se opõe ao teatro realizado por sua mãe, Irina Nicolaievna Arcadina, diva do teatro tradicional, e aos escritos de Boris Alexeievitch Trigorine. Embora a oposição resulte muito mais de questões sentimentais e psicológicas, Treplev defende um “teatro moderno” e é porta-voz das idéias de seu criador, Tchecov, que se enquadra nos postulados da escola realista russa do final do século XIX, tendo como principal recurso o simbolismo.

Treplev vive os tropeços de início de carreira, em busca do teatro moderno, sempre com a sensação de inferioridade que se evidencia quando comparado à carreira gloriosa de atriz de sua mãe Irina e ao sucesso de Trigorine, autor consagrado e amante de Irina. A relação entre Treplev e Irina não é harmoniosa, pelo contrário, é de enfrentamento: Irina vive em seu mundo de glamour, vangloria-se por ser uma diva do teatro tradicional e por seu sucesso em peças consagradas como A Dama das Camélias. Mãe e filho se digladiam verbalmente: Treplev ironiza a carreira da mãe e o teatro tradicional; Irina vive no mundo da fama e pouco se preocupa com o filho, considera-o um fracassado.

Além do embate entre mãe e filho, a peça pode ser considerada um estudo sobre o conflito entre gerações, pois se passa na propriedade de Sorine, um senhor de idade, irmão de Irina, que se sente infeliz por estar vivendo o final de sua vida no campo, quando gostaria de estar na cidade. A casa de 
campo é administrada pelo casal formado por Chamraev, tenente reformado, e Paulina. O casal tem uma filha chamada Macha, que nutre uma forte paixão por Treplev, mas o jovem escritor é apaixonado por uma jovem atriz estreante, Nina Mikhaievitch Zaretchnaia.

Inserindo o teatro no teatro, temos, logo que se inicia o primeiro ato, Nina encenando um trecho da primeira peça de Treplev. A encenação é interrompida, resultando em fracasso. Treplev fica deprimido e angustiado. Quando reencontra Nina, leva uma gaivota que ele matou, deposita-a nos pés da jovem e promete: "É assim que eu vou me matar não demora muito" (Idem, p. 49). Nina muda seu comportamento, desinteressa-se do namoro e se encanta por Trigorine, autor que sempre admirou, o qual também se encanta com a jovem atriz. Trigorine e Irina voltam para Moscou. Treplev nos conta que Nina o abandonou, decidiu fugir de casa e se tornou amante de Trigorine; engravidou, mas perdeu o filho e depois foi também abandonada. O sofrimento a tornou uma atriz medíocre. Macha casa-se com Medvedenco, professor que sempre esteve apaixonado por ela, mas se frustra na tentativa de esquecer o amor que sempre sentiu por Treplev. No último ato, Nina volta fracassada: não conseguiu sucesso como atriz e nem com seu amor. Na mesma época, retornam à casa de campo Trigorine e Irina, que restabeleceram o antigo romance. Treplev tornou-se um escritor de verdade, publica seus contos em revistas e recebe por esse trabalho. Quando Treplev reencontra Nina, confessa que o sentimento por ela é o mesmo. A atriz revela que também o ama, mas deve ir embora para cumprir um contrato. Quando estão conversando, Nina ouve a voz de Trigorine e vai embora. Nas últimas cenas, enquanto todos estão jogando, Chamraev, administrador da casa, entrega a Trigorine a gaivota que ele havia pedido para ser embalsamada. Ouve-se um tiro: Treplev se suicida.

Nádia Gotlib, em Clarice: Uma vida que se conta, procura examinar o entrelaçamento entre a narrativa de vida e a obra da escritora, estabelecendo relações entre dados de ordem biográfica e de textos ficcionais. Ao traduzir Tchecov, a própria escritora estabelece essa relação na crônica, mas agora se trata de um outro tipo de entrelaçamento entre vida e ficção, já que Clarice, leitora e tradutora, confessa que traduziu com esforço Tchecov, pois sentia que estava se descrevendo, vendo, como em um espelho, sua própria fisionomia.

Não tivemos acesso aos originais da tradução, uma vez que a própria Clarice afirma que o trabalho passou para as mãos de outra pessoa. Entre- 
tanto, a paráfrase acima nos evidencia em que espelho Clarice via sua imagem: a personagem protagonista Treplev também é escritor, buscando novas formas de expressão, mas se sente incompreendido. A angústia o conduz a um fim trágico - o suicídio.

Para nos situarmos cronologicamente, devemos nos lembrar que a crônica foi escrita em maio de 1968, ou seja, entre outras, a tradução de A gaivota também deve ter sido realizada na década de 1960. Dois fatos são marcantes nessa década: Clarice está separada de Paulo Gurgel Valente e se queima em incêndio em 1967. Em subitem dedicado a esse fato, "O acidente”, Nádia Gotlib nos dá a dimensão dessa conturbada década:

Enquanto isso, a vida de Clarice continua sem grandes acontecimentos de vulto, preocupada que se encontra com a educação dos dois meninos, com a saúde do filho mais velho, que mostra quadro de esquizofrenia a exigir cuidados especiais, e com as dificuldades financeiras no sentido de assegurar a sobrevivência.

(...)

E em 1967, novo fato marcante na sua vida. Na madrugada do dia 14 de setembro, Clarice sofre um acidente: há um incêndio no seu apartamento. Adormecera fumando e, ao acordar tenta apagar o fogo com as mãos. Tenta, também, salvar os papéis do escritório. E fica gravemente ferida sobretudo na mão direita, a que usava para escrever.

(...) Segundo o filho Paulo, "era vaidosa. Importava-se muito com sua aparência física, sua imagem. Depois do acidente, teve a mão direita e as pernas bastante queimadas, mamãe fechou-se muito. Mesmo assim, no final da vida, consultava-se com Tônia Carrero sobre moda, dicas de maquiagem e coisas deste tipo".

(...) Tal como este acidente, outros fatos de sua vida são considerados fatais. Entre eles, o próprio ato de escrever. (...)

Escrever, ler a mão, queimar a mão, escrever: eis um ciclo de fatalidades, um dos que constroem essa vida segundo Clarice Lispector. (GOTLIB, 1995, p. 367-368).

Esse ciclo de fatalidades é vivenciado por uma Clarice que se entrega ao ato de escrever: além de traduzir peças teatrais, sua produção literária tornase intensa. Agora, apoiados na própria afirmação de Clarice de que o protago- 
nista de A gaivota a denuncia, ${ }^{9}$ podemos afirmar que ambos são escritores e envolvidos por esse ciclo de fatalidades em que a escrita mais do que se configurar como tábua de salvação é tida também como uma fatalidade. Assim como Clarice roga por proteção - "Sinto-me tão desamparada, preciso tanto de proteção... por que parece que sou portadora de uma coisa muito pesada. Sei lá porque escrevo! Que fatalidade é esta? (...)” (LISPECTOR, 1984, p. 47), Treplev sente-se da mesma forma desamparado, desprotegido e essa sensação fica ainda maior para o protagonista diante do sucesso de sua mãe e do amante desta. O jovem escritor, em A gaivota, é solitário e está sempre em busca de um autoconhecimento: "Quem sou eu? O que sou?" e, no final da peça, passa a ser verdadeiramente um escritor, ganhando pelos artigos que publica em revista e despertando o interesse dos admiradores. Se Clarice ganha reconhecimento crítico, o sucesso a incomoda e a autora se nega a aceitar os rótulos que lhe tentam imprimir. Na crônica "Intelectual? Não.", Clarice refuta a idéia veiculada de ser uma intelectual para se autoquestionar e responder:

O que sou então? Sou uma pessoa que tem um coração que por vezes percebe, sou uma pessoa que pretendeu pôr em palavras um mundo ininteligível e um mundo impalpável. Sobretudo uma pessoa cujo coração bate de alegria levíssima quando consegue em uma frase dizer alguma coisa sobre a vida humana e animal. (LISPECTOR, 1999, p. 149)

A vinculação com a fatalidade, poderíamos dizer, torna Clarice e Treplev escritores dilemáticos, pois a escrita os consome na medida em que sentem necessidade de escrever e essa necessidade, além de não se completar, os deixa exauridos diante do texto escrito que lhes parece sempre inacabado. Além disso, a prática da escrita desmonta antigas concepções e ideais sobre

9 Embora não aprofundemos a questão, não podemos deixar de mencionar que a identificação que Clarice confessa ter com o protagonista pode ser estendida à personagem Boris Alexeievith Trigorine, que goza de reconhecimento também pela atividade de escritor e está sempre anotando idéias como assunto de uma nova novela, registrando detalhes da vida cotidiana. O registro iminente de fatos ou frases que o inspiram guarda certa semelhança com a escritora que tudo anotava em folhas de papel e até guardanapos para de pois transformar em seus contos e romances. 
novas formas de expressão. Assim, essa fatalidade guarda parentesco com a tortura, como chega a concluir Treplev:

$\mathrm{Eu}$ falava tanto em novas formas, mas aos poucos vou escorregando e ficando tão convencional quanto os outros. (...) É uma tortura. Cada vez me convenço mais que a questão não tem nada a ver com formas novas ou antigas, e, sim com o que flui livremente do coração, sem qualquer preocupação de forma. (TCHÉKOV, 2000, p. 88)

Treplev, que no início da peça buscava novas formas, condenando as tradicionais, conclui, portanto, que a preocupação com a forma é irrelevante, aproximando-se da afirmação de Clarice: "Gêneros não me interessam mais. Interessa-me o mistério” (LISPECTOR, 1999, p. 347).

Nesse sentido, a escritora, ao se identificar com a personagem protagonista, deve ter, da mesma forma, se identificado com seu criador, Tchecov. Podemos, assim, aproximar, resguardadas as diferenças, o estilo de Clarice ao de Tchecov, assinalado por James MacFarlane:

De modo geral, reconhece-se que sua originalidade consiste na habilidade com que cria uma atmosfera ou um estado de espírito, individual ou social. “A ação [de $A$ gaivota]”, escreveu Suvorin, "passa-se antes nos bastidores do que no palco, como se o autor estivesse interessado apenas em mostrar como as personagens reagiram aos fatos para revelar suas naturezas”. Por trás da fachada, sob a superfície, dentro da persona, submersa, reprimida - é lá, e dessa maneira, que se passa a ação. $\mathrm{O}$ meio da auto-revelação é o lugar comum, o irrelevante, o aparentemente superficial. (MacFARLANE, 1989, p. 427).

É possível estabelecer, de fato, semelhanças estilísticas entre os escritores em cuja obra o símbolo confere às coisas insignificantes um profundo conteúdo filosófico, em que o aprofundamento psicológico sobrepõe-se aos fatos em si e a introspecção é o lugar da ação.

Apesar das semelhanças estilísticas, Clarice afirma na crônica que traduziu com grande esforço $A$ gaivota, tendo ainda outro dissabor: a interferência do diretor na tradução que, às vezes, se julgava no direito de impor suas opiniões, mesmo que não tenha desenvolvido nenhuma pesquisa ou estudo para comprovar ou, pelo menos, convencer o tradutor da pertinência 
do que é imposto. Como se trata de uma peça teatral, Clarice nos relata o ocorrido com o diretor de teatro do qual ela e Tati Moraes discordavam:

Não nos incomodamos com a interferência justa de um diretor, tantas vezes esclarecedora, mas as divergências eram muito sérias. Entre outras, ele achava que, em vez de "angústia”, usássemos a palavra “fossa”. Ora, nós duas discordávamos: um personagem russo, ainda mais daquela época e ambiente, não falaria em fossa. Falaria em angústia e em tédio destruidor.

Como se pode observar, a crônica nos revela que as interferências no ato da tradução ora são requisitadas, como no caso da amiga-atriz Tônia Carrero, e contribuem para que a tradutora procure ser o mais fiel possível ao texto original; ora são incômodas e impertinentes, obstruindo inclusive o trabalho iniciado. Outras interferências, subjacentes ao ato da tradução, revelam a preocupação de amigos para com as possíveis identificações entre o protagonista da peça e Clarice. Há ainda aquelas em que o texto a ser traduzido é que passa a exercer certa interferência na rotina da vida pessoal da tradutora, influenciando até mesmo sua entonação.

Subjaz ainda na crônica a idéia de que o texto traduzido pode ser revelador dos dilemas e das angústias da autora e da pessoa Clarice Lispector que, ao traduzir e ser traduzida, coloca-se como que diante de um espelho, vendo uma imagem que dela se aproxima e com a qual se identifica, colocando em primeiro plano suas angústias e fraquezas. São interferências e espelhos que, como no ato da tradução, corre-se o risco de não acabar nunca!

\section{Traduzir procurando não trair}

Clarice Lispector ${ }^{10}$

Tati Moraes e eu traduzimos uma vez uma peça de Lilian Helman para Tônia Carrero levar. Fizemos a tradução com o maior prazer, se bem que de

10 Texto publicado na Revista Jóia, Rio de Janeiro, n. 177, maio de 1968. 
início eu tivesse que ser fustigada por Tati que é a minha inexorável feitora em vários terrenos, de trabalho ou não. Mas Tônia, você não imagina o trabalho de minúcias que dá traduzir uma peça. Ou melhor, você, que andou me dando sugestões inteligentes, imagina sim. Primeiro, traduzir pode correr o risco de não parar nunca: quanto mais se revê, mais se tem que mexer e remexer nos diálogos. Sem falar na necessária fidelidade ao texto do autor, enquanto ao mesmo tempo há a língua portuguesa que não traduz facilmente certas expressões americanas típicas, o que exige uma adaptação mais livre.

E a exaustiva leitura da peça em voz alta para podermos sentir como soam os diálogos? Estes têm que ser coloquiais: de acordo com as circunstâncias, ora mais ou menos cerimoniosos, ora mais ou menos relaxados.

Como se não bastasse, cada personagem tem uma “entonação” própria e para isso precisamos das palavras e do tom apropriados. Por falar em entonação, aconteceu-me uma coisa desagradável, enquanto durou a tradução. De tanto lidar com personagens americanos, “peguei” uma entonação inteiramente americana nas inflexões da voz. Passei a cantar as palavras, exatamente com um americano que fala português. Queixei-me a Tati, pois já estava enjoada de me ouvir, e ela respondeu com a maior ironia: “Quem manda você ser uma atriz inata”. Mas acho que todo escritor é um ator inato. Em primeiro lugar ele representa profundamente o papel de si mesmo. Escritor é uma pessoa que se cansa muito, e que termina com um pouco de náusea de si, já que o contato íntimo consigo próprio é por força prolongado demais.

Esta peça para Tônia foi ótima de se traduzir. Mas - e quando nos caiu em mãos uma peça de Tchecov? Veio numa fase em que eu estava meio deprimida. Depois eu soube que Tati andou consultando amigos meus para saber se me convinha lidar com o personagem principal, já que este se parecia demais comigo. A conclusão era que eu trabalhasse de qualquer maneira porque me faria bem agir, e porque seria bom eu ver, como num espelho, a minha própria fisinnomia. Que me faria bem lidar com um personagem cujo senso trágico da vida termina levando-o ao desespero. Traduzimos Tchecov, eu com um esforço tremendo, pois me parecia estar me descrevendo. Depois, por motivos externos, a peça passou para as mãos de outras pessoas, e perdemo-la de vista. Um dos motivos externos consistia no fato do diretor querer interferir demais na nossa tradução. Não nos incomodamos com a interferência justa de um diretor, tantos vezes esclarecedora, 
mas as divergências eram muito sérias. Entre outras, ele achava que, em vez de “angústia”, usássemos a palavra “fossa”. Ora, nós duas discordávamos: um personagem russo, ainda mais daquela época e ambiente, não falaria em fossa. Falaria em angústia e em tédio destruidor.

Mas, para falar a verdade, em termos atuais, ele estava era na fossa mesmo.

Em compensação, traduzimos “Hedda Gabler”, que não só foi logo encenada em São Paulo, como nos fez ganhar, com justo orgulho profissional, o prêmio da melhor tradução do ano. Uma medalha, meu Deus!

Prazer engraçado tive eu ao traduzir um livro condensado de Agatha Christie, encomendado por Tito Leite, diretor de Seleções. Em vez de lê-lo antes no original, como sempre faço, fui lendo à medida que ia traduzindo. Era um romance policial, eu não sabia quem era o criminoso, e traduzi com a maior pressa, pois não suportava a tensão da curiosidade. O livro esgotou-se rapidamente.

Traduzo, sim, mas fico cheia de medo de ter traduções que fazem de livros meus. Além de ter bastante enjôo de reler coisas minhas, fico também com medo do que o tradutor possa ter feito com um texto meu. Uma tradução de dois livros meus que fizeram para o alemão, não me causou problema: não entendo nada de alemão. E a coisa ficou aliviadoramente, por isso mesmo nem as críticas e comentários que a editora me mandou eu pude ler. Mas, quando um livro meu foi traduzido para o inglês, nos Estados Unidos, pela Knopf, - o livro saiu fisicamente lindo, bom até de se tocar com as mãos - então o problema foi outro. Eu sabia que o tradutor, Gregory Rabassa, era de primeira água - ganhou o "National Book Award” do ano, nos Estados Unidos, e inglês eu podia ler. Chamei-me então severamente à ordem, e comecei a cumprir meu dever de ler a mim mesma. A tradução me parece muito boa. Mas parei, pois o que venceu mesmo foi a náusea de me reler. O tradutor, professor de literatura portuguesa e brasileira numa universidade, fez um longo prefácio ao livro sobre literatura brasileira. Chegou à conclusão estranha de que eu era ainda mais difícil de traduzir que Guimarães Rosa, por causa de minha sintaxe. Não se assustem, nesta coluna esforço-me por não usar uma sintaxe que me é íntima e natural. Com um pouco de vergonha, já tinha esquecido o que quer dizer sintaxe. Perguntei a um amigo, que explicou: sintaxe é o modo como a frase se coloca dentro de 
um período. Fiquei um pouco na mesma. E também desconfiada de que não podia se tratar apenas disse: uma palavra tão grave quanto sintaxe não podia significar simplesmente isso. Tenho o maior respeito por gramática, e pretendo nunca lidar conscientemente com ela. Em matéria de escrever certo, escrevo mais ou menos certo de ouvido, por intuição, pois o certo sempre soa melhor.

\section{BIBLIOGRAFIA}

GOTLIB, Nádia Battella. Clarice: Uma vida que se conta. São Paulo: Ática, 1995.

JAKOBSON, Roman. "A tradução intersemiótica ou transmutação consiste na interpretação dos signos verbais por meio de sistemas de signos não-verbais”. In: Lingüística e comunicação. Trad. de Izidoro Blikstein e José Paulo Paes. São Paulo: Cultrix, 1969.

LISPECTOR, Clarice. “Aventura”, em Para não esquecer. São Paulo: Ática, 1984.

LISPECTOR, Clarice. “Intelectual? Não.”, em A descoberta do mundo. Rio de Janeiro: Rocco, 1999.

LISPECTOR, Clarice. "Traduzir procurando não trair". Revista Jóia, n. 177, Rio de Janeiro, maio de 1968.

MacFARLANE, James. "O teatro intimista - De Maeterlinck a Strindberg”. In: BRADBURY, Malcolm \& MacFARLANE, James. Modernismo: Guia geral 18901930 (trad. de Denise Bottmann). São Paulo: Companhia das Letras, 1989.

TCHÉKOV, Antón. A gaivota. Trad. de Bárbara Heliodora. São Paulo: EDUSP, 2000. 